\title{
Influence of Optic Nerve Appearance on Visual Outcome in Pediatric Idiopathic Intracranial Hypertension
}

\author{
Jonathan A. Micieli@, Beau B. Bruce, Caroline Vasseneix, Richard J. Blanch, \\ Damian E. Berezovsky, Nancy J. Newman, Valérie Biousse, Jason H. Peragallo
}

\begin{abstract}
Objectives: To determine whether optic disc hemorrhages (ODH) and cotton wool spots (CWS) at presentation are associated with worse visual outcomes in pediatric patients with idiopathic intracranial hypertension (IIH). Methods: Retrospective institutional review of 100 eyes of 50 consecutive pediatric IIH patients (aged 16 years or less) who had baseline optic disc photographs before or within 30 days of their diagnostic lumbar puncture and initiation of medical treatment. Optic disc photographs were independently graded by three ophthalmologists in a standardized manner. Visual function was assessed using visual acuity (VA) and visual field grade (VFG). Results: At least one ODH was found in $41 \%$ of eyes, at least one CWS was found in $27 \%$ of eyes, and $20 \%$ of eyes had both ODH and CWS. At presentation, Frisén grade was associated with the presence of CWS $(p=0.013)$ and showed no association with ODH $(p=0.060)$. When controlling for Frisén grade, ODH and CWS were not associated with worse VA or VFG at final follow-up. Severe ODH were associated with worse VA and VFG at presentation $(p<0.03)$, but not at final follow-up. Severe CWS at presentation was strongly associated with a worse Humphrey mean deviation of $5.0 \mathrm{~dB}(95 \%$ confidence interval 1.6-8.3) at final follow-up $(p=0.002)$. Conclusion: When controlling for the severity of papilledema, ODH do not provide any additional prognostic value in pediatric IIH patients. Frisén grade and severe CWS at presentation were independently associated with worse visual outcomes at the final follow-up.
\end{abstract}

RÉSUMÉ : Impact de l'apparence du nerf optique sur des résultats à des tests visuels dans le cas de jeunes patients atteints d'hypertension intracrânienne idiopathique. Objectif: Déterminer dans quelle mesure des foyers hémorragiques des disques optiques (FHDO) et des nodules cotonneux (cotton wool spots) peuvent être associés à de moins bons résultats à des tests visuels chez des jeunes patients atteints d'hypertension intracrânienne idiopathique (HII). Méthodes: Nous avons effectué au sein d'un établissement un examen rétrospectif des yeux $(n=100)$ de 50 patients âgés de 16 ans ou moins et atteints d'HII chez qui on avait au départ photographié les disques optiques. À noter que ces photographies ont été prises 30 jours avant une ponction lombaire diagnostique et le début d'un traitement médical ou dans les 30 jours suivant cet examen et ce traitement. Elles ont été ensuite classées de manière indépendante et standardisée par trois ophtalmologistes. Quant à la fonction visuelle de ces patients, elle a été évaluée au moyen de tests d'acuité visuelle (AV) et de tests d'exploration du champ visuel (ECV). Résultats: Au moins un FHDO a été détecté pour $41 \%$ des yeux ; de plus, au moins une trace de nodules cotonneux a été observée pour $27 \%$ des yeux ; enfin, $20 \%$ des yeux ont donné à voir à la fois un FHDO et une trace de nodules cotonneux. Au moment où ces patients se sont présentés, on a pu associer leurs scores à l'échelle de gradation de Frisén à la présence de nodules cotonneux $(p=0,013)$ tandis qu'aucune association n'a pu être notée avec des FHDO $(p=0,060)$. Une fois contrôlés en fonction de l'échelle de gradation de Frisén, tant les FHDO que les nodules cotonneux n'ont pas été associés, lors d'un dernier suivi, à de plus faibles résultats à des tests d'AV et d'ECV. Des FHDO d'une plus grande gravité ont certes été associés à de moins bons résultats à ces tests lorsque les patients se sont initialement présentés $(p<0,03)$; ce n'était toutefois plus le cas lors d'un dernier suivi. Notons enfin que des traces de nodules cotonneux d'une plus grande gravité au moment où les patients se sont initialement présentés se sont révélées, selon l'analyseur de champ Humphrey, fortement associées à un écart-moyen plus faible de 5,0 dB (IC 95\% 1,6-8,3) au moment d'un dernier suivi $(p=0,002)$. Conclusions: Une fois contrôlés en fonction de la gravité d'un œdème papillaire, les FHDO ne fournissent aucune valeur pronostique supplémentaire chez des jeune patients atteints d'HII. Les scores à l'échelle de gradation de Frisén et des traces de nodules cotonneux d'une plus grande gravité au moment où ces patients se sont présentés ont été ainsi indépendamment associés à de moins bons résultats à des tests visuels lors d'un dernier suivi.

Keywords: Papilledema, Idiopathic intracranial hypertension

doi:10.1017/cjn.2020.89

Can J Neurol Sci. 2020; 47: 661-665

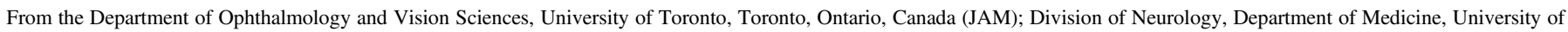

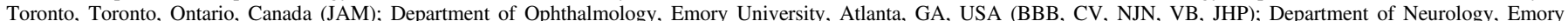

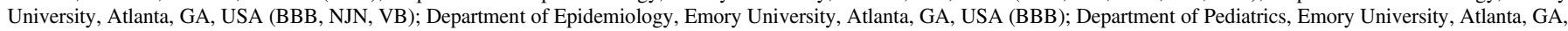

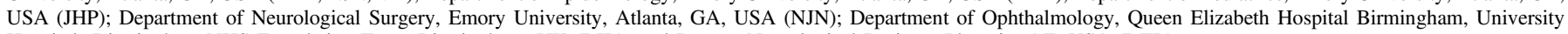
Hospitals Birmingham NHS Foundation Trust, Birmingham, UK (RJB); and Barrow Neurological Institute, Phoenix, AZ, USA (DEB)

Received November 17, 2019. Final Revisions Submitted March 31, 2020. Date of Acceptance April 25, 2020.

Correspondence to: Jason H. Peragallo, Neuro-Ophthalmology Unit, Emory Eye Center, 1365-B Clifton Rd. NE, Atlanta, GA 30322, USA. Email: jason.peragallo@emory.edu 


\section{INTRODUCTION}

Idiopathic intracranial hypertension (IIH) is a syndrome characterized by symptoms and signs of intracranial hypertension without an identifiable cause. ${ }^{1}$ Although IIH primarily affects obese women of childbearing age, ${ }^{2,3}$ it may also affect patients in the pediatric age-group. ${ }^{4}$ Pediatric IIH patients present with symptoms similar to adults, such as headache, transient visual obscurations, diplopia, blurred vision, and cranial nerve deficits but may also have some differences when compared with adults. These differences include a lower frequency of obesity and a more equal sex distribution, especially in prepubertal children. ${ }^{5}$ Older children with IIH were found to be more likely obese and female, similar to the epidemiology of adults. ${ }^{6}$

Patients with IIH and papilledema are at risk of irreversible vision loss and optic atrophy. Risk factors for a poor visual outcome include the severity of papilledema at presentation, which has been found both in pediatric ${ }^{7}$ and in adult patients. $^{8-10}$ The Idiopathic Intracranial Hypertension Treatment Trial (IIHTT) proposed that optic disc hemorrhages (ODH) may be a risk factor for poor visual outcome in adults since this was a more frequent finding in the treatment failure group. ${ }^{11} \mathrm{We}$ performed a study of 708 eyes of 360 adult IIH patients and found that $\mathrm{ODH}$ and peripapillary cotton wool spots (CWS) were not an independent risk factor for a poor visual outcome in IIH when controlling for the severity of the papilledema. ${ }^{9}$ The goal of this study was to determine whether optic nerve appearance, particularly ODH and CWS, were an independent risk factor for visual outcome in pediatric IIH.

\section{Subjects ANd Methods}

This study was approved by Emory University's Institutional Review Board and conducted in compliance with the US Health Insurance Portability and Accountability Act of 1996. As previously described in detail, ${ }^{9} 1244$ consecutive patients with IIH diagnosed according to the modified Dandy criteria ${ }^{12}$ seen at our institution between January 1, 1989, and March 31, 2017, were retrospectively reviewed. Clinical information, details from a full neuro-ophthalmology evaluation at baseline, and follow-up examinations were retrieved. Snellen visual acuity (VA) was converted to $\log$ MAR VA for analysis. Visual field information was recorded as the Humphrey mean deviation (MD) and defects were given a visual field grade (VFG) from 1 to 4 as used previously, ${ }^{9,13,14}$ where 1 was normal, 2 was an enlarged blind spot, 3 was a nasal or temporal defect, and 4 represented diffuse constriction.

\section{Inclusion and Exclusion Criteria}

Only pediatric patients 16 years of age or less at presentation with fundus photographs obtained at presentation were included in the study. Patients were excluded if they received surgical treatment prior to initial fundus photographs, had optic atrophy or gliosis at initial presentation, or had their diagnostic lumbar puncture or medical treatment more than 30 days prior to initial fundus photographs. In patients with unilateral papilledema, only the eye with papilledema was included in the study.

\section{Photograph Grading}

Fundus photographs were reviewed by three independent ophthalmologists (JAM, RJB, and CV) in a standardized fashion as described previously. ${ }^{9}$ Papilledema was graded according to the modified Frisén scale, which is defined as a scale from 0 to 5 , where grade 0 is normal, grade 1 is very early papilledema (obscuration of the nasal border of the optic disc), grade 2 is early papilledema (obscuration of all borders of the optic disc), grade 3 is moderate papilledema (obscuration of one or more segments of major blood vessels as they leave the optic disc), grade 4 is marked papilledema (obscuration of a segment of a major blood vessel on the optic disc itself), and grade 5 is severe papilledema (dome-shaped protrusion with obscuration of all vessels on the optic disc). ${ }^{15} \mathrm{ODH}$ within one disc diameter of the optic disc were categorized as nerve fiber layer, subretinal, or pre-retinal hemorrhages. Both ODH and CWS were classified as mild (1-5 individual ODH/CWS), moderate (6-15 individual ODH/CWS), or severe (more than $15 \mathrm{ODH} / \mathrm{CWS}$ or 2 or more clock hours of continuous ODH/CWS $)^{9}$ The quadrant with at least one CWS/ $\mathrm{ODH}$ was recorded. An independent neuro-ophthalmologist (VB or NJN) resolved disagreements regarding the presence or severity of $\mathrm{ODH}$ and CWS or discrepancies in Frisén grade if less than two reviewers agreed on the Frisén grade for each eye.

\section{Statistical Analysis}

Statistical analysis was performed with R: A language and environment for statistical computing ( $R$ Foundation for Statistical Computing, http://www.R-project.org).

Data collected through summary measures, including medians and interquartile ranges for skewed data, and proportions for categorical variables were subject to a univariate analysis. Between-group comparisons were performed using $t$-tests, $\chi^{2}$ tests, and Fisher's exact tests, as appropriate. Linear regression models on logMAR VA and Humphrey MD and ordinal logistic regression on VFG were used to examine the associations among risk factors with outcomes controlling for Frisén grade, body mass index (BMI), Black race, and sex. Intraclass correlation coefficient was used to measure the interrater reliability and was determined using the variance components from a one-way analysis of variance. Significance at the 5\% level was used as the cutoff for statistical significance. Results were reported as the median (interquartile range) or mean \pm standard deviation.

\section{ReSUlts}

A total of 100 eyes of 50 pediatric IIH patients were included in the study. The median age at diagnosis was 14 (4-16) years and included 12 patients between ages 3 and 11, 17 patients between ages 12 and 14, and 21 patients who were 15 or 16 years of age. Girls comprised the majority of patients, $41(82 \%)$ of 50 and $21(42 \%)$ of 50 were of Black race; the mean BMI was $32.4 \pm 10.2 \mathrm{~kg} / \mathrm{m}^{2}$ and the mean opening pressure was $45.4 \pm 10.0 \mathrm{~cm}$ of water. Median follow-up time was 55.1 weeks (interquartile range 25.4-87.7). Humphrey visual fields were obtained in $36(72 \%)$ of 50 of patients and the average MD at presentation was $-6.00 \pm 4.83 \mathrm{~dB}$. Initial fundus photographs were obtained before diagnostic lumbar puncture in $46 \%$ of patients and within 2 weeks of diagnostic lumbar puncture in the remainder of patients. A large majority of patients were treated with acetazolamide $(86 \%)$, three underwent optic nerve sheath fenestration, and seven underwent cerebrospinal fluidshunting procedures. 


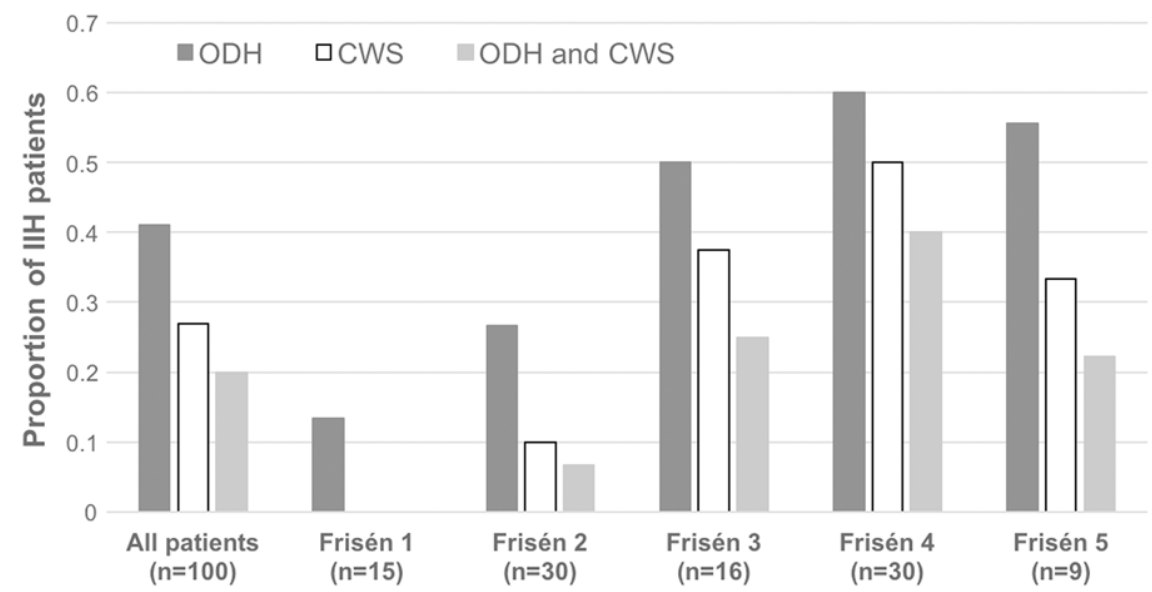

Figure 1: Proportion of pediatric idiopathic intracranial hypertension $(\mathrm{IIH})$ patients with optic disc hemorrhages $(O D H)$, cotton wool spots $(C W S)$, or the combination of ODH and CWS by severity of papilledema indicated by the Frisén grade. At presentation, the presence of ODH showed no association with Frisén grade $(p=0.060)$ and CWS were associated with Frisén grade $(p=0.013)$.

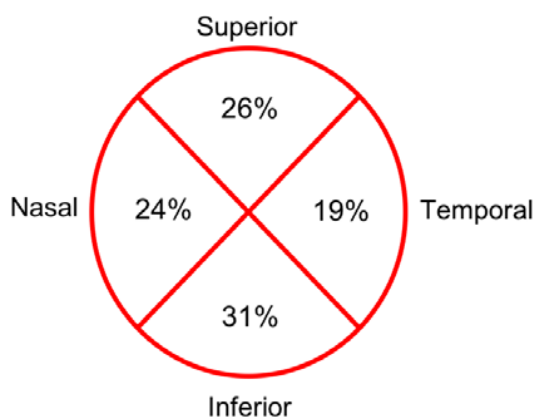

Optic disc hemorrhages

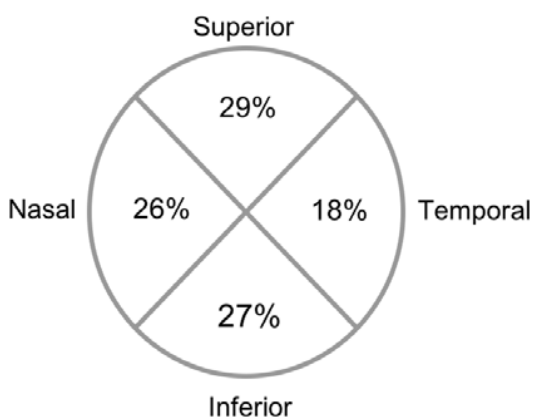

Cotton wool spots

Figure 2: Distribution of optic disc hemorrhages and cotton wool spots at presentation based on location on the optic disc.

Mild papilledema including Frisén grade 1 was found in $15 \%$ of patients and Frisén grade 2 was found in $30 \%$ of patients. More severe papilledema including Frisén grades 3, 4, and 5 were found in $16 \%, 30 \%$, and $9 \%$ of eyes, respectively. There was good agreement among Frisén grading with an intraclass correlation coefficient of 0.70 (95\% confidence interval, CI, 0.51-0.77). A third reviewer was required on 14 cases (grade 5 in one case, grade 4 in six cases, grade 3 in two cases, and grade 2 in five cases). Among 100 pediatric IIH eyes, at least one ODH was found in 41 eyes, at least one CWS in 27 eyes, and 20 eyes had both ODH and CWS (Figure 1). The most frequent location for ODH was the inferior quadrant $(31.0 \%)$, followed by the superior (26.2\%), nasal (23.8\%), and temporal (19.0\%) quadrants (Figure 2). CWS were most frequent in the superior quadrant (28.9\%), followed by the inferior $(26.8 \%)$, nasal $(26.3 \%)$, and temporal (17.9\%) quadrants (Figure 2). All ODH were nerve fiber layer hemorrhages and no subretinal or pre-retinal hemorrhages were observed.

At presentation, the presence of $\mathrm{ODH}$ showed no association with Frisén grade $(p=0.060)$, while CWS were associated with
Frisén grade $(p=0.013)$. All of the severe ODH and $83 \%$ of the severe CWS (83\%) were present in individuals with Frisén grade 4 or 5 (Figure $3 \mathrm{~A}$ and $\mathrm{B}$ ). When controlling for age, BMI, gender, and race, Frisén grade correlated with worse VFG at presentation $(p=0.01)$ and worse final VA when controlling for initial VA $(p=0.02)$. When controlling for Frisén grade, BMI, race, and gender, the overall presence of ODH or CWS was not associated with worse VA and VFG at initial presentation or final follow-up. Severe ODH at presentation were associated with a worse VA and VFG at initial presentation but not final follow-up $(p<0.03)$. Severe CWS at presentation were strongly associated with a worse Humphrey MD (5.0 dB loss, 95\% CI 1.6-8.3) controlling for Frisén grade and other variables. Severe CWS was also associated with abnormal final VFG at final follow-up [odds ratio $(\mathrm{OR})=15$ ] before control for other variables, but due to quasi-complete separation the OR for VFG could not be accurately estimated (lower bound of the $95 \%$ CI was 7). However, among patients with a Humphrey visual field, the MD was $5 \mathrm{~dB}$ lower (95\% CI: 1.6-8.3) for those with severe CWS at presentation than those without after controlling for Frisén grade and 
A

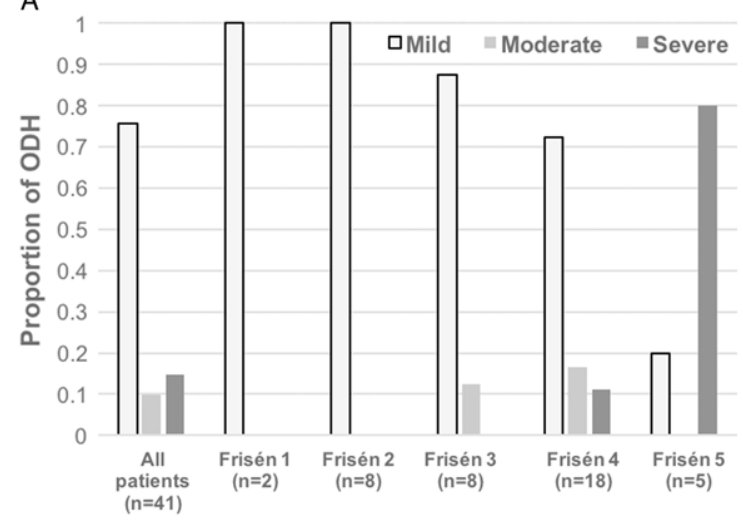

B

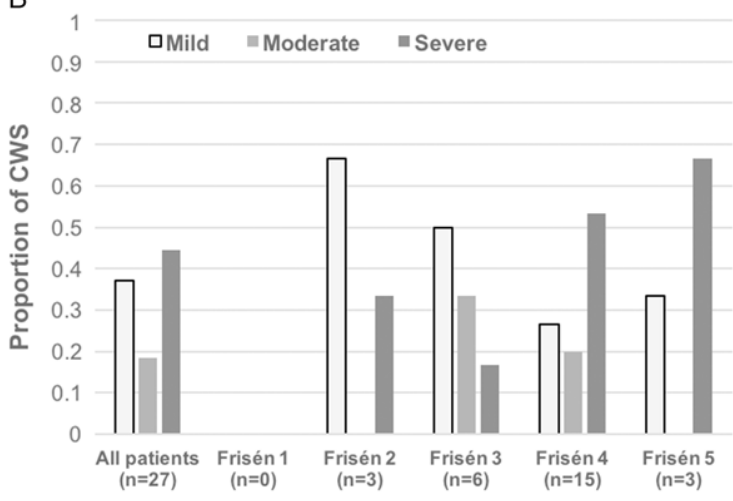

Figure 3: Proportion of patients with pediatric idiopathic intracranial hypertension (IIH) with (A) optic disc hemorrhages $(O D H)$ and $(B)$ cotton wool spots $(C W S)$ stratified by Frisén grade. ODH and CWS severity was classified as mild (1-5 individual ODH/CWS), moderate (6-15 individual ODH/CWS), or severe (more than 15 individual ODH/CWS or two or more clock hours of continuous $\mathrm{ODH} / \mathrm{CWS}$ ).

other variables. Final VA was worse than 20/100 in $4(4 \%)$ eyes and VFG was 3 or 4 in $20(20 \%)$ eyes.

\section{Discussion}

In our cohort of pediatric IIH patients, final VA correlated with the severity of papilledema but the final visual function (VFG or VA) did not correlate with the overall presence of ODH or CWS at presentation when controlling for the Frisén grade of papilledema. However, severe CWS at presentation were strongly associated with an abnormal final MD and VFG. There was no association between Frisén grade and ODH and a significant association between Frisén grade and CWS at presentation, suggesting that $\mathrm{ODH}$ and CWS are markers of more severe papilledema. This was similar to what was found in a similar study of adult IIH patients. ${ }^{9}$ However, there was a higher prevalence of $\mathrm{ODH}(41.0 \%$ vs $28.4 \%)$ and CWS $(27.0 \%$ vs $14.3 \%$ ) in our pediatric IIH series compared to adults. ODH and CWS were more prevalent in the inferior and superior quadrants where the nerve fiber layer is the thickest. ${ }^{16}$

Risk factors for a poor visual outcome in IIH include the severity of papilledema, ${ }^{8-10}$ "fulminant" disease course,${ }^{17}$ men,${ }^{14}$ Black patients, ${ }^{13}$ and those with coexisting hypertension, ${ }^{18}$ anemia, ${ }^{19}$ and morbid obesity. ${ }^{20}$ Although some of these papers ${ }^{13,17,20}$ included individuals less than 16 years of age, the overwhelming majority of patients were adults. A recent study by Gospe et al. ${ }^{7}$ found that the severity of papilledema was a risk factor for a poor visual outcome in 31 pediatric IIH cases. Our study supports the finding in that Frisén grade at presentation was associated with worse final VA and also adds an additional poor prognostic factor of severe CWS at presentation. It was suggested that ODH may be a marker of poor visual prognosis by the IIHTT, ${ }^{11}$ but this was not found to be the case in our previous study of adults ${ }^{9}$ and in this cohort of pediatric IIH patients when controlling for the severity of papilledema. In the IIHTT, ODH as a predictor of worse visual outcome was not assessed independent of Frisén grade, which is likely the reason for the differences in our studies.

Our series of pediatric IIH patients was similar in terms of visual outcomes compared to those of previous series. Permanent visual field defects were found in $20 \%$ of eyes and this was comparable to the $17 \%$ of permanent visual field defects reported in the series by Phillips et al. $^{21}$ and $19 \%$ of patients with permanent VA or visual field loss reported by Gospe et al. ${ }^{7}$ Previous studies on children with raised intracranial pressure reported a prevalence of ODH of $16 \%$ and in a series of 29 children with dural venous sinus thrombosis, 4 (22\%) of 18 individuals with papilledema had splinter disc hemorrhages. ${ }^{23}$ However, these studies did not assess the prognostic value of ODH. Many of the blood vessels on the surface of the optic disc are venous in nature with very thin walls prone to rupture. As the papilledema progresses in severity, there is compression of the main retinal veins and a greater likelihood of severe hemorrhaging, which is why the severity of ODH has been associated with the Frisén grade of papilledema. ${ }^{9}$ CWS are localized accumulations of axoplasmic debris thought to be due to focal inner retinal ischemia. ${ }^{24}$ The presence of multiple CWS may reflect more severe axoplasmic flow stasis and inner retinal ischemia, conferring a higher chance of a poor visual outcome.

The strengths of this study include the relatively large number of pediatric IIH patients and the broad sample of various degrees of vision loss, representing the spectrum of IIH seen in clinical practice. Differences in the management of these pediatric IIH patients were unlikely to be a contributing factor, since clinical decisions were made by the same neuro-ophthalmologists over the study period. Limitations of this study include the retrospective nature and the inherent limitations of using the Frisén scale, which is a subjective grading scale, when assessing the severity of papilledema, and future studies may aim to use optical coherence tomography measures. ${ }^{25}$ However, there was good interrater reliability of Frisén grading, and only 14 cases had significant disagreements as to Frisén grading requiring adjudication. Most disagreements were regarding the presence or absence of blood vessel obscuration leaving or on the disc, which was largely subjective. When grading as mild, moderate, or severe, there was little disagreement, which is most important in clinical practice. It is possible that ODH may have resolved before their initial fundus photograph due to interventions such as lumbar puncture, but by only including patients with fundus photographs within 30 days of their initial diagnostic lumbar 
puncture, we were able to limit this possibility. To allow for the comparison of patients who have had Humphrey and Goldmann visual fields, the VFG was utilized per the previous studies on IIH and visual outcome. ${ }^{9,13,14}$ Subtle visual field defects would not be captured by this scale, but our goal was to include the most significant and meaningful defects seen in patients with IIH. Moreover, visual field testing is difficult in the pediatric population. Given that the study took place in a tertiary care center with expertise in IIH, the higher prevalence of ODH and CWS may reflect more severe cases referred to this center. An additional limitation of our study is the small number of patients under 12 years of age $(n=12)$, which suggests that our study population is comprised of a preponderance of postpubertal children. As a result of this limitation, a meaningful statistical analysis of our presumed prepubertal and postpubertal children was not possible.

In conclusion, ODH did not provide any prognostic value in patients with pediatric IIH when controlling for the severity of papilledema and other risk factors known to predispose to a poor visual outcome. Frisén grade at presentation was associated with worse VA at final follow-up and was associated with the presence of CWS and at presentation. Severe CWS at presentation were also associated with a worse visual field at final follow-up, suggesting that these patients and those with more severe papilledema should be monitored closely to prevent a poor visual outcome.

\section{FUNDING}

This study was supported in part by an unrestricted departmental grant (Department of Ophthalmology) from Research to Prevent Blindness, Inc., New York, and by NIH/NEI core Grant P30-EY006360 (Department of Ophthalmology). Dr Biousse received research support from NIH/PHS (UL1-RR025008). Dr Newman is a recipient of the Research to Prevent Blindness Lew R. Wasserman Merit Award. Dr Vasseneix is the recipient of the Philippe Foundation Inc. grant.

\section{CONFLICT OF INTEREST}

No conflicting relationship exists for any author.

\section{Statement of Authorship}

Conception and design: JAM, BBB, NJN, VB, and JHP; data collection: JAM, CV, RJB, and DEB; data analysis: JAM, CV, RJB, DEB, and BBB; drafting of manuscript: JAM and JHP; critical analysis: BBB, CV, RJB, DEB, NJN, VB, and JHP; final approval: NJN, VB, JHP, and BBB.

\section{REFERENCES}

1. Wall M. Update on idiopathic intracranial hypertension. Neurol Clin. 2017;35(1):45-57.

2. Ireland B, Corbett JJ, Wallace RB. The search for causes of idiopathic intracranial hypertension: a preliminary case-control study. Arch Neurol. 1990;47(3):315-20.
3. Wall M, George D. Idiopathic intracranial hypertension: a prospective study of 50 patients. Brain. 1991;114(Pt 1A):155-80.

4. Rangwala LM, Liu GT. Pediatric idiopathic intracranial hypertension. Surv Ophthalmol. 2007;52(6):597-617.

5. Phillips PH, Sheldon CA. Pediatric pseudotumor cerebri syndrome. J Neuroophthalmol. 2017;37(Suppl 1):S33-40.

6. Balcer LJ, Liu GT, Forman S, et al. Idiopathic intracranial hypertension: relation of age and obesity in children. Neurology. 1999;52(4):870-2.

7. Gospe SM, 3rd, Bhatti MT, El-Dairi MA. Anatomic and visual function outcomes in paediatric idiopathic intracranial hypertension. Br J Ophthalmol. 2016;100(4):505-9.

8. Wall M, Falardeau J, Fletcher WA, et al. Risk factors for poor visual outcome in patients with idiopathic intracranial hypertension. Neurology. 2015;85(9):799-805.

9. Micieli JA, Bruce BB, Vasseneix C, et al. Optic nerve appearance as a predictor of visual outcome in patients with idiopathic intracranial hypertension. $\mathrm{Br} \mathrm{J}$ Ophthalmol. 2019;103(10): 1429-35.

10. Orcutt JC, Page NG, Sanders MD. Factors affecting visual loss in benign intracranial hypertension. Ophthalmology. 1984;91(11): 1303-12.

11. Wall M, Thurtell MJ, NORDIC Idiopathic Intracranial Hypertension Study Group. Optic disc haemorrhages at baseline as a risk factor for poor outcome in the Idiopathic Intracranial Hypertension Treatment Trial. Br J Ophthalmol. 2017;101(9):1256-60.

12. Dandy WE. Intracranial pressure without brain tumor. Ann Surg 1937;106(4):492-513.

13. Bruce BB, Preechawat P, Newman NJ, Lynn MJ, Biousse V. Racial differences in idiopathic intracranial hypertension. Neurology. 2008;70(11):861-7.

14. Bruce BB, Kedar S, Van Stavern GP, et al. Idiopathic intracranial hypertension in men. Neurology. 2009;72(4):304-9.

15. Scott CJ, Kardon RH, Lee AG, Frisen L, Wall M. Diagnosis and grading of papilledema in patients with raised intracranial pressure using optical coherence tomography vs clinical expert assessment using a clinical staging scale. Arch Ophthalmol. 2010;128(6):705-11.

16. Jonas JB, Budde WM, Panda-Jonas S. Ophthalmoscopic evaluation of the optic nerve head. Surv Ophthalmol. 1999;43(4):293-320.

17. Thambisetty M, Lavin PJ, Newman NJ, Biousse V. Fulminant idiopathic intracranial hypertension. Neurology. 2007;68(3): 229-32.

18. Corbett JJ, Savino PJ, Thompson HS, et al. Visual loss in pseudotumor cerebri: follow-up of 57 patients from five to 41 years and a profile of 14 patients with permanent severe visual loss. Arch Neurol. 1982;39(8):461-74.

19. Biousse V, Rucker JC, Vignal C, et al. Anemia and papilledema. Am J Ophthalmol. 2003;135(4):437-46.

20. Szewka AJ, Bruce BB, Newman NJ, Biousse V. Idiopathic intracranial hypertension: relation between obesity and visual outcomes. J Neuroophthalmol. 2013;33(1):4-8.

21. Phillips PH, Repka MX, Lambert SR. Pseudotumor cerebri in children. J AAPOS. 1998;2(1):33-8.

22. Binenbaum G, Rogers DL, Forbes BJ, et al. Patterns of retinal hemorrhage associated with increased intracranial pressure in children. Pediatrics. 2013;132(2):e430-4.

23. Binenbaum G, Reid JE, Rogers DL, et al. Patterns of retinal hemorrhage associated with pediatric cerebral sinovenous thrombosis. J AAPOS. 2017;21(1):23-7.

24. McLeod D. Why cotton wool spots should not be regarded as retinal nerve fibre layer infarcts. Br J Ophthalmol. 2005;89(2): 229-37.

25. Sinclair AJ, Burdon MA, Nightingale PG, et al. Rating papilloedema: an evaluation of the Frisen classification in idiopathic intracranial hypertension. J Neurol. 2012;259(7):1406-12. 